\title{
2009: The year of innovations in the European Spine Journal
}

\author{
Max Aebi $\cdot$ Li-Yang Dai
}

Accepted: 17 April 2009/Published online: 23 April 2009

(C) Springer-Verlag 2009

Further to our first announcement in the March 2009 issue, we are pleased to promote now in this issue the second innovation of this year.

In order to offer our Chinese colleagues an international platform to publish their work in spinal sciences, the Editorial Board of the European Spine Journal has decided to establish a Chinese section within the journal. It goes with the intention and recommendation of the Chinese Academy of Science to encourage particularly young Chinese scientists to publish in international scientific journals to expose themselves to international standards and to benchmark their work. It is so more important to establish the knowledge flow from China to the western established science world than the other way round. Those Chinese colleagues who are familiar with the English language have already since long read the English literature and promoted this knowledge in their country.

Instructions for manuscript submissions: manuscripts for the Chinese Section have to be uploaded via Editorial Manager (http://www.editorialmanager.com/esjo/) under the newly-created "Chinese section". Manuscript submissions have to comply with the instructions of the European Spine Journal (see instructions for authors).

\section{Aebi ( $\square)$}

MEM Research Center for Orthopaedic Surgery,

Institute for Evaluative Research in Orthopaedic Surgery,

University of Bern, Stauffacherstrasse 78,

3014 Bern, Switzerland

e-mail: max.aebi@MEMcenter.unibe.ch

URL: http://www.MEMcenter.unibe.ch

L.-Y. Dai

Department of Orthopaedic Surgery, Xinhua Hospital,

School of Medicine, Shanghai Jiaotong University,

200092 Shanghai, China
The Chinese language, however, should not be the barrier to expose innovative and relevant research out from China to the rest of the world.

For this reason the European Spine Journal has created a Chinese Section Editorial Board to which authors can submit their articles in Chinese language. This Chinese Section Editorial Board will select the best papers, have them translated in English and published in agreement with the Editor-in-Chief in the European Spine Journal. These selected articles will then be published in Chinese as well as in English language and will give the international spinal community access to important scientific insight and knowledge independent from the language. Hopefully, this measure will bring the international scientific community concerned with the spine closer to each other.

M. Aebi

Editor-in-Chief

L.-Y. Dai

Deputy Editor "Chinese Section" 